\title{
Human rights and health inequalities of migrants
}

\author{
Qian SUN \\ Nanjing University \\ Nanjing, China
}

Jianyun BAO

Visiting scholar of University of Chicago

Chicago, U.S.A.

ucbaojy@gmail.com

\author{
Zhenzhong DENG \\ School of Medicine \\ University of Tokyo \\ Tokyo, Japan \\ dengzhenzhong11@gmail.com
}

\author{
Youguo ZHANG* \\ College of Political Science and Law, \\ Capital Normal University \\ Beijing, China \\ * corresponding author youguozhang1@sina.com
}

\begin{abstract}
- the reform and opening up, the development of legal migrants and management of the market economy provides the institutional basis. However, human rights as one of the core human rights law, especially for economic development and urban construction has made important contributions to the migrants who were not able to get real protection. Based on this background to build a harmonious society, the law should not just manage the floating population, but should play an important role in the protection of human rights of migrants. Medical benefits significantly improve the flow of population willingness to buy health insurance, but it is has no significant impact on the flow of population health care spending. Medical benefits of the floating population health investment will have a significant positive incentive effects, but it does not improve the flow of population health investment capacity. The reason may be related to the separation of urban and rural health care system, the researchers demonstrate the robustness tests to be descriptive statistical analysis and modeling of two angles. In addition, there are gender differences in the flow of population health investment behavior.
\end{abstract}

\section{Keywords-) migrants; human rights; health}

\section{INTRODUCTION}

\section{A. Migration and Social Development}

From the point of view of human nature, migration is a human instinct avoiding disadvantages and is the inevitable product of the history of human evolution and social development. In today's China market economy, migration is economic development process re-allocation of labor resources market performance, it can reduce the excess surplus agricultural labor to bring heavy pressure on land, to avoid unnecessary waste of human resources, but also for the urgent need regional labor and industry it provides abundant labor. Therefore, a reasonable population movement is a necessary condition for the healthy development of the social economy, and it can effectively promote economic and social development. On the one hand, migration is conducive to the development of the rural economy, the transfer of agricultural labor is to ease the people, land conflicts, and promote moderate scale land operations, increase the efficiency of agricultural production. Meanwhile, the promotion of non-agricultural development, strength and growth of the rural economy accelerates agricultural modernization. On the other hand, population movement promotes urbanization and urban economic development, urban agricultural labor inflows for the prosperity and development of urban economy has contributed to bringing the inevitable result of the migration of convenience to local residents living and working in the floating population production. The so-called floating population usually refers to a certain time frame, across geographic boundaries and changed some people to live. Because the management of China's population is mainly achieved through the household registration system, so in our country, migrants refers people leaving domicile and engaging in various activities in the field of population, or those living in the inflow without local identity.

\section{B. Situation of human rights of migrants}

Human rights as a person according to their natural attributes and social nature should enjoy rights enjoyed by a citizen of any society, they must have in order to prevail in the household registration system which began in 1958 in the "People's Republic of China account regulations." Under the ordinance, urban housing system, food supply system, food and fuel supply, production, supply system, education system, health care system, pension system, labor protection system, employment system and even the institution of marriage have fundamentally different aspects. Although more than 50 years when, in all aspects of the country changes dramatically occur, but whether it has a place of permanent residence, and the ability to enjoy the residence of health care, pension, labor protection, education and other welfare system are closely related. 


\section{HUMAN RIGHTS AND RULE OF LAW}

Human rights are the core of the rule of law. The rule of law means that people's behavior is subject to the law, but the law has become a control person's inner nature, and even as a means of human behavior, outside the scope of the law, everyone is free. But the law itself is legitimate; it is also an important factor affecting the rule of law and it can become an effective means of establishing a harmonious society. Although in theory, the law is a manifestation of the will of the members of society, but on the one hand it is due to the possibility of national politics, on the other hand it is due to the democratic principles of majority itself is a helpless choice, the law does not in fact represent the common interests of all members of society, which is difficult to stop those laws which may become more of a political advantage to achieve their own interests. So if the content of law is tyranny, it is obviously contrary to the rule of law and building a harmonious society.

\section{RULES OF LAW AND HARMONIOUS SOCIETY}

The rule of law is a prerequisite for a harmonious society. Society is a human colony, to form harmonious relations between people; otherwise we can not guarantee everyone's normal life. For example, if there is no uniform requirements' orderly traffic lights, then everyone's life is at risk. In general, human behavior is controlled by its own ideas, and this idea has come from life experience and wisdom to survive. So, if the concept of the life experience of most people and results are similar, most people are likely to self-discipline, so that society can be more of an orderly existence. But with the expansion of the scope of human activity and interaction, life experiences and ideas thus formed between people are different, and people follow their own original ideas to life, it is not necessarily greater survival capacity and life wisdom. Thus, to the original concept of influence and we can not be an effective means to control people's behavior.

Respect and protection of human rights is to build a harmonious society, an important condition for the rule of law. The rule of law is inseparable from the idea of harmony, which has become the consensus of the legal community. Themes in Beijing at the "22nd World Congress on the Law" is the "rule of law and international harmonious society", and the aim is to "build a harmonious society ruled by law," the World Association of Law. Harmony means "coordination" means "the various elements of society, including the individual and the whole, a good combination between the whole methodically run smoothly. The "people-oriented is the starting point to build a harmonious socialist society and the end result," which means harmony between people is based on respect for humanity inevitable, personality and people-oriented basis. Only when the legal rights are of all people, for all, freedom and creativity are respected, harmonious society is in order to have a solid foundation. Respect for human rights are not real, it's not a harmonious society, only the legitimate rights of members of the society which are duly respected and protected, it may have to speak of social harmony that is only effective protection of human rights of a group in order to achieve the establishment of "democracy and the rule of law, justice, sincerity, amity, vitality, stability and order, target man and nature live in harmony society ".

\section{FLOATING POPULATION HEALTH}

Only $58.38 \%$ of the floating population has health insurance, but only $5.42 \%$ of the floating population enjoys the national medical subsidies to buy health insurance, floating population in most countries did not enjoy medical benefits. The floating population of migrant workers in the field accounted for $79.94 \%$, while only $18.67 \%$ is local migrant workers, the household registration system may be an important factor in the floating population to enjoy the national health insurance subsidies, while $74.12 \%$ of migrants work in the private or individual units, and there is $54.12 \%$ of the migrants who are working without a contract status, migrants important factor in urban work units to buy health insurance may also be affected. In short, there is a big difference in the flow of population health investment behavior. According to that the floating population health investment behavior has occurred, from healthy willingness investment (the behavior does not occur) and healthy investment capacity (behavior has occurred), the two angles are to the empirical analysis of the factors, but compare the difference between the empirical results can discriminate floating population health investment behavior, and in the end it is a rational choice to invest their personal health, or the government implements the incentive effects of medical subsidies?

\section{A. effects of Medicaid health willingness to invest}

Medical benefits at the $1 \%$ level have significant positive impact on population health investment and it will flow to reflect the medical subsidy investment and help to improve the health of migrants. Personal-care expenditures in the $5 \%$ significance level has positive impact on population health investment, that is, personal care, the stronger, the stronger willingness to invest in their health. The average monthly income of migrants will affect the health of the investment and it is not significant, which reflects no significant effect relationship between income and willingness to buy health insurance floating population, and it seems to contradict the impression of reality, because for most people of a more reasonable logic income, the more healthy the strong willingness fro them to invest. The reason presented no significant causal relationship between population health investment and earnings was mainly caused because of its special status, migrants domicile is not their place of residence on the one hand, due to the integration of urban and rural health care are not effectively implemented limited medical benefits, this can account variables from the regression results and confirm some empirical results to show that compared to local agriculture accounts staff, field staff healthy agriculture accounts willingness to invest is much weaker; on the other hand they live and work in the city and it is not only required to pay higher the cost of living, coupled with lower income levels, without medical benefits, then living in the city between migrants may rarely 
considered as normal healthy investment issues, of course, there exist among such descriptive statistical analysis expressed as the vast majority of migrants who lack awareness of health investment. Willingness to invest in the health model, health care subsidies could improve the flow of population health willingness to invest, but the income and health investment will no causal link empirical sense, this kind of floating population in the dirty and messy and other health risks is due to higher operating and their own health needs are not consistent with the objective conclusion, it is true whether express willingness to invest in the health of migrants, namely medical benefits really improve the flow of population health investment will, therefore, we intend to further investigate the flow of research investment capacity of the medical health of the population subsidies effects. Rural migrant's human rights protection systems for rural migrants are to build social scientific management, it should be changed to prevent the main active acceptance, establish a new concept of rural migrants in harmony with the public interest mycorrhizae.

\section{B. reform of deepening the household registration system Residents}

Currently, the household registration system is undoubtedly lying in rural migrants into the urban society in front of the hardest barriers. For rural migrants already living in the inflow of long-term and that part of the population becoming the de facto resident, to solve the problem of their account, not only can they get fair and equitable treatment of citizens in many ways, but also they can promote their active integration into the city life. And they still have some liquidity for that part of the population, household registration reform will give them more choices. Innovative rural migrant's rights protection and system innovation system's goal is to eliminate all forms of discrimination against rural migrants and ensure their access to national treatment, to achieve social justice.

Public service building mechanisms to obtain gradient progressive in the case of the household registration system is still not fully liberalized and rural migrants to provide appropriate services and management, urban residence permit system in the implementation of all the floating population has a certain inevitability and possibilities. Residence permit system for building richer rural migrants efficiency of public service delivery mechanism provides a suitable carrier, which can be considered the basis residence management system, construction of public service to obtain gradient progressive mechanism.

\section{CONCLUSIONS}

Constitution uses protecting and fulfilling human rights as a starting point and destination. Protect the human rights aspects of rural household registration system and the impact of dual social security system of inequality employment system, rural migrants in employment, equal pay, social security, education, etc. and their children are missing. Therefore, we should establish the concept of public service interest's symbiont, deepen the reform of the household registration system for residents, make innovative rural migrant's rights protection system, and build public services to obtain gradient progressive mechanism to fully protect the human rights of rural migrants.

\section{References}

[1] Su Xiaoxin Health behavior and health care utilization of urban migrant population studies [D]. Fudan University,2012.

[2] Xiang Yicai. benefit the Chinese people to learn the value of social security measure to deal with the reality of research [D]. Huazhong University of Science and Technology,2012.

[3] Wang Heng research of China's urban population security issues[D] Southwestern University of Finance and Economics,2013.

[4] Zhan Wei Qing Human rights and education [D]. Central China Normal University,2006.Lack of institutional protection of human rights of rural migrants to build

[5] Xie Wenjun, Li Shan Dong - based on the constitutional perspective [J] Hunan Agricultural University (Social Sciences), 2011,06: 50-55.

[6] Jiang Shouhuo. Improve the flow of population health care utilization [D]. Fudan University, 2008 